\title{
MAKNA SIMBOLIK TORTOR TOPING HUDA-HUDA DALAM UPACARA ADAT SAYURMATUA PADA MASYARAKAT SIMALUNGUN SUMATERA UTARA
}

\author{
Suci Rahmadani ${ }^{1^{*}}$, Erlinda $^{2^{*}}$ \\ Minat Studi Pengkajian Seni Tari Program Pascasarjana \\ Institut Seni Indonesia Padangpanjang \\ Jl. Bahder Johan, Guguak Malintang, Padangpanjang, Kota Padangpanjang, 27126. \\ Sumatera Barat. Indonesia \\ Email: sucieramadhani12@gmail.com
}

\begin{abstract}
Abstrak
Tortor toping huda-huda adalah pemberian penghormatan kepada orang tua yang telah meninggal, yang merupakan suatu bentuk kesenian tradisi yang secara turun temurun diwarisi oleh masyarakat Simalungun untuk memenuhi kebutuhan upacara adat sayurmatua. Upacara adat sayurmatua adalah ritual upacara kematian, dimana sayurmatua merupakan orang tua yang sudah lanjut usia meninggal dunia, yang mana orang tua tersebut sudah memiliki cucu dari anak laki-laki dan anak perempuannya. Upacara adat sayurmatua terdapat 2 pembagian acara yaitu mandingguri dan manggiligi. Tortor toping huda-huda ditampilkan dalam acara mandingguri. Dalam pelaksanaan upacara adat sayurmatua terdapat beberapa acara kemudian terdapat musik dan tari di dalamnya yaitu gonrang sipitu-pitu, , tortor manggiligi, dan tortor toping huda-huda. Tujuan penelitian ini adalah mengungkap makna yang terkandung pada tortor toping huda-huda dan pelaksanaan tortor toping huda-huda dalam upacara adat sayurmatua di Simalungun Sumatera Utara. Metode yang digunakan adalah metode kualitatif, pengumpulan data dilakukan melalui observasi dan mengamati upacara adat sayurmatua, khususnya pertunjukan tortor toping huda-huda yang terkait dengan upacara, kemudian didukung oleh dokumentasi audio dan visual serta wawancara dengan sejumlah tokoh adat dan masyarakat. Penelitian ini dianalisis dengan teori Semiotika oleh Ferdinand De Sausurre.
\end{abstract}

Kata Kunci: upacara, sayurmatua, tortor toping.

\begin{abstract}
Tortor toping huda-huda is giving respect to deceased parents, which is a form of traditional art that has been inherited from the Simalungun community for the needs of the adat vegetable ceremony. The sayurmatua traditional ceremony is a ritual death ceremony, where sayurmatua is an elderly parent who has passed away, in which the parents already have grandchildren from their sons and daughters. There are 2 adat divisions of the sayurmatua ceremony, namely the mandingguri and mujukigi. Tortor toping huda is displayed in the mandingguri program. In the implementation of the sayurmatua traditional ceremony there are several events then there are music and dance in it, namely gonrang sipitu-pitu, tortor manggiligi, and tortor toping huda-huda. The purpose of this study was to reveal the meaning contained in tortor toping huda-huda and the implementation of tortor toping huda-huda at the sayurmatua traditional ceremony in Simalungun, North Sumatra. The method used is a qualitative method, data collection is carried out through observation and observing the vegetablematua traditional ceremony, especially the tortor toping huda-huda performance related to the ceremony, then supported by audio and visual documentation and interviews with a number of traditional leaders and the community. This study was analyzed by Semiotic theory by Ferdinand De Sausurre.
\end{abstract}

Keywords: ceremony, sayurmatua, tortor toping.

\section{PENDAHULUAN}

Simalungun merupakan salah satu kabupaten yang terdapat di daerah Sumatera Utara. Penduduk asli dari daerah ini yaitu Suku Batak Simalungun. Masyarakat Simalungun menganut agama Kristen Protestan/ Katolik, Islam, dan terdapat juga agama pendatang seperti agama Budha dan Hindu. Simalungun memiliki berbagai macam kesenian, dari kesenian yang berfungsi untuk hiburan sampai kesenian yang difungsikan untuk upacara - upacara seperti upacara perkawinan, upacara panen dan upacara kematian.

Upacara kematian merupakan suatu pemberian penghormatan terakhir kepada orang yang sudah meninggal. Pada masyarakat Simalungun, mereka 


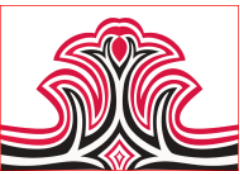

sangat menghormati orang yang sudah meninggal, mereka melakukan sesi-sesi upacara kematian sampai upacara pemakaman. Menurut salah satu Seniman di Simalungun yaitu Hendrik, mengatakan bahwa "menjadi suatu kebanggan dan menjadi sempurna hidupnya jika orang tuanya meninggal dunia dalam keadaan sayurmatua”.

Sayurmatua merupakan orang yang meninggal dunia disaat dia telah memiliki anak yang semuanya sudah mandiri dan berkeluarga juga telah memiliki cucu. Ketika seseorang tersebut meninggal dalam keadaan sayurmatua maka dilakukanlah proses upacara sayurmatua, yang mana pada upacara sayurmatua ini terdapat beberapa kesenian yaitu seperti tari dan musik. Salah satunya yaitu Tortor toping huda-huda.

Penari pada tortor toping huda-huda ini berjumlah 3 orang penari diantaranya yaitu 2 orang penari menggunakan toping dalahi dan toping naboru, kemudian 1 orang penari huda-huda.Tortor toping huda-huda ditampilkan pada saat manggiliki yaitu suatu acara yang dilakukan pada siang hari untuk menyambut para pelayat. Tortor toping huda-huda merupakan salah satu tarian yang bersifat religius. Tortor toping huda-huda sudah menjadi kesenian tradisi turun temurun yang hadir pada ritual upacara sayurmatua.

Masyarakat Simalungun tetap melakukan ritual upacara ini karena sudah menjadi tradisi turun temurun semenjak zaman kerajaan di Simalungun dahulunya. Disetiap gerak pada Tortor toping hudahuda mengandung makna dan simbol yang terkait pada hubungan manusia dengan manusia, dan hubungan manusia dengan tuhan. Menurut Ferdinand De Saussure (dalam Abdul Chaer, 1994:286) mengungkapkan bahwa pengertian makna adalah sebagai suatu konsep yang dimiliki atau terdapat pada suatu tanda linguistic, dalam proses untuk mengetahui makna, yang perlu dipahami adalah pola pikir harus sesuai dengan penerapan yang berstruktur baik dalam bentuk lisan maupun tulisan. Dalam menetapkan sebuah makna, perlu adanya sistem tanda-tanda yang disebut dengan simbol. Simbol ataupun makna merupakan bagian terpenting dalam kehidupan masyarakat. Proses terjadinya simbol, apabila subjek berhadapan dengan realita yangmenciptakan sebuah makna-makna tertentu, maka muncullah proses simbolik.

Simbolik merupakan perihal pemakaian simbol untuk mengeksplorasi ide-ide misalnya seni dan sastra (Sugono dalam Kusumawardani, 2008:3). Menurut
Gorga Jurnal Seni Rupa

Volume 08 Nomor 01 Januari-Juni 2019

p-ISSN: 2301-5942 | e-ISSN: 2580-2380

hayakama, proses simbolik terdapat pada semua tingkat peradaban manusia dari paling sederhana sampai yang telah maju, dari kelompok masyarakat bawah sampai kelompok yang paling atas (Hayakawa, 1949:25). Proses simbolik akan digunakan untuk memberikan kedalaman tentang seni, seperti maknamakna yang terdapat pada gerakkan tortor toping huda-huda dalam upacara sayurmatua.

Berdasarkan penjelasan diatas, dapat disimpulkan, ada beberapa Rumusan masalah untuk mengungkap makna simbolik tortor toping hudahuda dalam upacara adat sayurmatua pada masyarakat Simalungun Sumatera Utara, Rumusan masalah dari penelitian ini yaitu :

Bagaimana pelaksanaan Tortor toping huda-huda dalam upacara sayurmatua pada masyarakat Simalungun Sumatera Utara

Apa makna simbol yang terkandung pada Tortor toping huda-huda dalam upacara sayurmatua pada masyarakat Simalungun Sumatera Utara

Tujuan dari penelitian ini adalah untuk mengetahui Pelaksanaan tortor toping huda-huda dalam upacara kematian sayurmatua pada masyarakat Simalungun Sumatera Utara.

Makna simbol tortor toping huda-huda dalam upacara kematian sayurmatua pada masyarakat Simalungun Sumatera Utara.

\section{KAJIAN TEORI}

Pemecahan dari masalah tersebut diperlukan pendapat teori-teori yang berkaitan yaitu Teori Semiotika Ferdinand De Sausurre seorang ahli bahasa dari Swiss. Menurut pakar linguistik, Ferdinand De Sausurre, semiotika adalah kajian mengenai "kehidupan tandatanda dengan masyarakat yang menggunakan tandatanda itu. Ferdinand De Sausurre melihat tanda sebagai pertemuan antara bentuk dan makna. Sausurre menggunakan istilah signifiant (signifer:penanda) untuk segi bentuk suatu tanda, signifie (signified: petanda) untuk segi maknanya. De saussure melihat tanda sebagai sesuatu yang menstruktur (proses pemaknaan berupa kaitan antara penanda dan petanda) dan terstruktur ( hasil proses tersebut) di dalam kognisi manusia. Dengan demikian, apa yang ada dalam kehidupan dilihat sebagai "bentuk" yang mempunyai "makna" tertentu. jadi, hubungan antara bentuk dan makna tidak bersifat pribadi tetapi sosial yang didasari oleh "kesepakatan" (konvensi) sosial. (Sausurre dalam Hoed, 2008:3-4). 


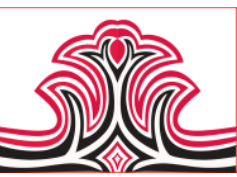

Kemudian dalam menganalisis makna simbolik dalam penelitian ini adalah tentang makna simbolik tortor toping huda-huda yang terdapat dalam upacara sayurmatua pada masyarakat Simalungun Sumatera Utara, digunakan teori penafsiran yang dikemukakan Victor Turner (dalam Endaswara, 2006:173) yaitu

Exegetical meaning yaitu makna yang diperoleh dari informan warga setempat tentang perilaku ritual yang diamati. Dalam hal ini, perlu dibedakan antara informasi yang diberikan oleh informan awam dan pakar. Seorang peneliti juga harus mengetahui pasti apakah penjelasan yang diberikan oleh informan benar-benar representatif dan atau hanya penjelasan dari pandangan pribadi yang unik;

Operational meaning yaitu makna yang diperoleh tidak terbatas pada perkataan informan, melainkan dari tindakan yang dilakukan dalam ritual. Pengamatan seharusnya tidak hanya mempertimbangkan simbol tetapi sampai pada interpretasi struktur dan susunan masyarakat yang menjalankan ritual;

Positional meaning yaitu makna yang diperoleh melalui interpretasi terhadap simbol dalam hubungannya dengan simbol lain secara totalitas, atau dengan kata lain makna simbol ritus ditafsirkan ke dalam konteks simbol yang lain dan pemiliknya.

\section{METODE PENELITIAN}

Penelitian ini berupa penelitian kualitatif menggunakan metode deskriptif analisis dengan tujuan agar masalah yang dianalisis dapat diinterpretasikan secara jelas. Peneliti mengawali penelitian dengan melakukan survey terlebih dahulu ,Peneliti bertemu langsung dengan beberapa narasumber dan melakukan wawancara, dengan tujuan memperoleh data awal untuk memulai kegiatan penelitian. Selanjutnya peneliti melakukan observasi sebagai tindak lanjut penelitian lapangan mengamati langsung tortor toping huda-huda yang terdapat pada upacara sayurmatua. Observasi merupakan salah satu teknik pengumpulan data untuk mendapatkan data melalui pengamatan terhadap fenomena sosial dengan berbagai gejala yang berhubungan dengan objek penelitian. Kemudian pengamatan diperkuat dengan wawancara dan pendokumentasi peristiwa yang terjadi pada upacara sayurmatua. Wawancara dilakukan dengan para informan yang terlibat dalam upacara sayurmatua maupun tortor toping huda-huda Wawancara dilakukan secara langsung, mendalam dengan gaya bebas dan memakai pedoman wawancara berupa daftar pertanyaan untuk membantu lancarnya
Gorga Jurnal Seni Rupa

Volume 08 Nomor 01 Januari-Juni 2019

p-ISSN: 2301-5942 | e-ISSN: 2580-2380

wawancara. Wawancara didukung oleh beberapa instrument seperti handphone,handycam, tipe recorder, dan kamera digital. Kamera digunakan untuk mengambil gambar atau merekam kejadian pada saat penelitian dilapangan sebagai data penelitian.

\section{HASIL DAN PEMBAHASAN \\ 1.Hasil}

Indonesia memiliki berbagai macam kebudayaan disetiap daerahnya. Kebudayaan adalah keseluruhan yang kompleks yang di dalamnya terkandung ilmu pengetahuan, kepercayaan, kesenian, moral, hukum, adat istiadat, dan kemampuan serta kebiasaan yang didapatkan oleh manusia sebagai anggota masyarakat tertentu. Kebudayaan akan mewarnai anggota masyarakat karena kebudayaan akan melandasi tingkah laku dan kebiasaan manusia di dalam kehidupan, sesuai dengan norma-norma, salah satunya adalah adat istiadat atau tata kelakuan yang mengikat anggota masyarakat tertentu. Dimana kebudayaan merupakan sebagai keseluruhan sistem gagasan, tindakan dan hasil karya manusia dalam rangka kehidupan masyarakat yang dijadikan milik diri manusia dengan belajar ( Koentjaraningrat, 1990: 193 239).

Salah satu daerah yang masih kental sistem kebudayaannya di dalam masyarakat yaitu di daerah Sumatera Utara Kabupaten Simalungun. Simalungun memiliki berbagai macam adat istiadat yang sudah menjadi tradisi warisan turun temurun yang masih dilestarikan masyarakat setempat salah satunya tradisi upacara adat kematian. Kematian menurut kamus bahasa Simalungun disebut dengan namatei, kemudian kematian di Simalungun terdapat beberapa macam sifat kematiannya dan setiap penamaan dari kematian itu pun berbeda-beda, salah satunya ada upacara sayurmatua, sayurmatua artinya upacara kematian terhadap orang tua yang lanjut usia, dimana dia telah memiliki anak yang semuanya sudah mandiri dan berkeluarga juga telah memiliki cucu. Upacara sayurmatua hanya dilakukan untuk penghormatan kepada orang tua yang lanjut usia dan sudah memiliki cucu dari anak perempuannya dan cucu dari anak lakilakinya. Upacara sayurmatua hanya berlaku jika yang meninggalnya itu dalam keadaan sayurmatua.

Sayurmatua merupakan orang yang meninggal dunia disaat dia telah memiliki anak yang semuanya sudah mandiri dan berkeluarga juga telah memiliki cucu. Menurut masyarakat Simalungun, kematian seseorang merupakan suatu hal yang harus dihormati dengan mengadakan acara adat istiadat, karena jika seseorang yang meninggal dunia telah memiliki anak yang 
semuanya sudah mandiri dan berkeluarga dan memiliki cucu. Maka orang yang meninggal tersebut dianggap telah sempurna menurut adat Simalungun. Ketika seseorang tersebut meninggal dalam keadaan sayurmatua maka dilakukanlah proses upacara sayurmatua. Menurut masyarakat Simalungun menjadi suatu kebanggan dan menjadi sempurna hidupnya jika orang tuanya meninggal dunia dalam keadaan sayurmatua. Tujuan dilakukannya upacara sayurmatua tersebut supaya keturunannya semua panjang umur seperti dia dan supaya mereka memiliki harta kekayaan seperti yang meninggal, harta kekayaan menurut orang Simalungun itu adalah anak, cucu dan cicitnya.Upacara sayurmatua ini terdapat beberapa kesenian yaitu seperti tari dan musik. Salah satunya yaitu Tortor toping huda-huda.

Tortor toping huda-huda merupakan suatu bentuk kesenian tradisi yang secara turun temurun diwarisi oleh masyarakat Simalungun untuk memenuhi kebutuhan upacara sayurmatua. Tortor toping hudahuda ditampilkan pada saat acara manggiliki yang terdapat di dalam rangkaian upacara sayurmatua, yaitu suatu acara yang dilakukan pada siang hari untuk menyambut tondong ( tulang atau paman) yang disebut mangalo-alo dengan toping huda-huda. Maknanya agar menghargai tondong yang datang dan menghormatinya. Penari pada toping huda-huda ini berjumlah 3 orang diantaranya yaitu 1 penari menggunakan toping naboru (topeng yang berbentuk wajah perempuan) dan 1 penari menggunakan toping dalahi (topeng yang berbentuk wajah laki-laki), kemudian 1 penari menggunakan huda-huda (penari yang memakai topeng yang menyerupai badan kuda dan memakai paruh burung onggang).

Tortor toping huda-huda berada ditengah-tengah masyarakat Simalungun dari zaman kerajaan di Simalungun sampai saat ini, mereka tetap melakukan ritual upacara adat ini karena sudah menjadi tradisi turun temurun. di dalam tari ini terdapat gerak yang mengandung simbol dan makna untuk penghormatan terakhir dan penyembahan kepada roh-roh yang telah meninggal. Dimana masyarakat Simalungun mempercayai bahwa burung enggang (onggang) yang dipakai penari tortor toping huda-huda dianggap tertinggi dan seperti raja, dan ketika seseorang yang meninggal itu raja atau derajatnya paling tinggi dan berdarah biru, maka disudut makamnya diletakkan simbol paruh burung enggang (onggang).

Iringan musik tortor toping diiringin dengan hagualon. Hagualon adalah jenis dalam gonrang simalungun.hagualon berasal dari kata'gual' (tabuh)
Gorga Jurnal Seni Rupa

Volume 08 Nomor 01 Januari-Juni 2019

p-ISSN: 2301-5942 | e-ISSN: 2580-2380

bisa di artikan tata cara memukul(menabuh) gonrang dengan rumus tertentu dan tetap (tidak bisa diubahubah).alat musiknya seperti gong, mongmongan, dan sarunei yang erupakan komponen dari ansambel musik gonrang simalungun yang tersusun atas sebuah sarunei, dua buah alat tabuh yaitu gonrang sidua-dua, satu buah ongmongan, dan sebuah tawak-tawak atau siappuk (gong bernada tinggi). Gual yang digunakan dalam tortor toping huda-huda adalah gual huda-huda.

\section{Pembahasan}

Tortor toping huda-huda ini pertama kali ditampilkan pada saat kerajaan Simalungun. Awal mulanya Tortor toping huda-huda digunakan untuk menghibur puangbolon (istri raja) yang terus menerus menangis, karena puteranya telah meninggal dunia, dan puangbolon tidak bisa merelakan kematian anaknya. Bahkan seisi istana telah membujuk puangbolon agar rela menguburkan anak yang dikasihinya itu, namun tetap saja bujukan memakamkan itu ditolaknya. Masalah puangbolon yang tidak ingin memakamkan anaknya yang sudah meninggal telah menjadi buah bibir di lingkungan istana dan seisi kampung. Pada suatu hari, berkumpullah masyarakat yang disebut dengan paragat (pengambil nira), mereka berkumpul dan berunding bagaimana caranya anak raja bisa dikebumikan.

Jadi mereka mengambil satu kesepakatan untuk membuat kekacauan di kampung, dan mereka terinspirasi dengan burung onggang yang besar dan monyet, jadi mereka membuat baju seperti burung, Topeng yang menyerupai wajah yang meninggal. dan paruh enggang dikemas menjadi main-mainan (onjabonjab) dengan cara menambahkan hiou menutup tubuh yang memakai topeng dan kepala burung enggang, sementara itu, untuk meniru burung enggang, maka ditambahkan ekor yang terbuat dari rotan (hotang). Kemudian mereka menyamarkan tubuh nya yang memakai paruh burung enggang tadi seluruh mukanya ditutup dengan kain, dan di kepalanya dikenakan paruh dan kepala enggang serta dibuat ekornya dengan memakai rota. Dan dua orang lainnya hanya menggunakan topeng dan menutup tubuhnya memaki hiou. Kemudain mereka sudah membuat rencana dengan raja bahwa mereka akan membuat kekacauan di kampung dengan membawa alat musik tradisional Simalungun, saat mereka menari masyarakat ada yang heran, terkejut, ketakutan, dan ada yang menangis. kemudian, puangbolon ingin melihat kekacauan yang terjadi dikampung, sehingga tanpa sadar dia meninggalkan anaknya di istana, saat puangbolon meninggalkan anaknya, raja langsung 
mengambil anaknya dan memberikan ke penjaga istana untuk dibumikan.

Sejak itu, tortor toping huda-huda selalu ditampilkan pada saat adanya keluarga raja yang meninggal. Setelah runtuhnya kewibawaan kerajaan Simalungun, maka tari toping huda-huda diadaptasi oleh masyarakat Simalungun menjadi mandingguri atau manggiliki yang ada pada upacara sayurmatua. Maka Tortor toping huda-huda di tampilkan pada saat sayurmatua (orang yang meninggal pada usia lanjut) dan masih keturunan raja. Maka pertunjukan Tortor toping huda-huda boleh dilaksanakan sebagai hiburan bagi keluarga yang ditinggalkan.

Tortor toping huda-huda ditampilkan pada saat manggiliki yaitu suatu acara yang dilakukan pada siang hari untuk menyambut para pelayat..Fungsi tarian ini adalah sebagai media simbolik memaknai kematian yang dilakonkan melalui gerak ritmis sebagai ekspresi jiwa atau rasa dalam memaknai kematian itu sendiri. Tortor toping huda-huda merupakan salah satu tarian yang bersifat religius. Nilai religius tortor toping huda-huda terletak pada padung ni onggang ( paruh burung enggang), karena dianggap sebagai burung paling besar di simalungun, dan burung enggang dianggap bahwa dapat mendatangkan berkat dan melambangkan kesuburan apabila burung enggang lewat disuatu desa. Dan menurut orang simalungun, burung enggang akan membawa roh yang telah meninggal untuk menghadap yang kuasa.

Penari pada tortor toping huda-huda ini berjumlah 3 orang penari diantaranya yaitu 2 orang penari menggunakan toping dalahi dan toping naboru, kemudian 1 orang penari huda-huda. Tortor toping huda- huda diadakan waktu ada acara kematian yang berfungsi sebagai hiburan untuk mengalihkan perhatian keluarga yang bersedih. Di dalam tortor toping huda-huda terdapat unsur - unsur musikologis yang mencerminkan kedukaan, kesedihan maupun derita atau lara akibat kehilangan anggota keluarga yang dicintainya. Gerak tari dalam tortor toping hudahuda sangatlah sederhana, hanya gerakan dasar tortor dihar (pencak silat), geraknya mengikuti gual yang dimainkan, tidak ada gerak yang diatur. Tortor toping huda-huda dilakukan di halaman rumah orang yang sedang berduka.

Penari toping naboru dan toping dalahi memiliki rambut yang terbuat dari ijuk dan topeng laki-laki memiliki kumis pada topengnya. Sedangkan topeng perempuan memiliki giwang ( anting-anting) pada
Gorga Jurnal Seni Rupa

Volume 08 Nomor 01 Januari-Juni 2019

p-ISSN: 2301-5942 | e-ISSN: 2580-2380

telinga topeng. Kemudian topeng huda-huda menggunakan kain putih yang menutupi setengah badannya dan dikepala menggunkan paruh burung enggang. Busana yang digunakan penari toping dalahi taitu celana panjang hitam, surisuri berwarna biru gelap, hiou berwarna biru gelap dengan motif ragi sattik, dan baju polang-polang (warna belang-belang) yang terdiri dari warna hitam, putih, merah dan membawa bahul-bahul (kantong anyaman yang diselempangkan ) untuk menerima uang dari para keluarga yang menyaksikan. Sedangkan penari toping naboru menggunakan surisuri berwarna merah, hati rongga berwarna merah, baju polang-polang dan membawa bahul-bahul. Untuk penari huda-huda hanya menggunakan kain penutup dari atas kepala sampai mata kaki yang berwarna sama dengan penari toping dan membawa padung ni onggang. Kemudian hadang-hadangan (selendang) pria dan wanita diletakkan dibahu sebelah kanan. Filosofinya adalah letak dan posisi hadang-hadangan sama seperti kain gendongan untuk menggendong anak.

Tortor toping huda-huda berada ditengah-tengah masyarakat Simalungun yang menganut agama Kristen Protestan di Simalungun. Masyarakat Simalungun memiliki sistem kepercayaan yang masih mempercayai roh-roh yang telah meninggal, dimana adanya pertalian antara "roh-roh" dalam upacara adat yang menurut pemahaman orang Simalungun, masih ada koneksi diantara manusia yang masih hidup di dunia tengah ( nagori tongah) dengan manusia yang sudah mati di dunia bawah (nagori toruh) (wawancara dengan bapak Hendri Damanik, 2018). Orang Simalungun percaya bahwa naibata sebagai oknum ilahi tertinggi itu bermanifestasi dalam diri tiga dewa yang menguasai tiga alam dunia (kosmos). Naibata sebagai oknum ilahi ini diyakini menguasai seluruh kosmos baik dunia atas, kediaman para dewa (nagori atas), dunia tengah, kediaman manusia (nagori toruh). Masing-masing dunia kosmos itu dipercaya dikuasai ilahi semacam Trimurti. Nagori tongah tempat manusia hidup dikuasai oleh dewa tuan tobal dunia, Nagori toruh tempat para jin dan orang mati dikuasai oleh tuan padukah ni aji dan nagori atas tempat para dewata dan orang-orang baik nan suci dikuasai oleh tuan Sahine-hine.

Koentjaraningrat (1990:200) juga membedakan tiga wujud kebudayaan yang ia sebut: pertama wujud kebudayaan sebagai suatu kompleks ide, gagasan, nilai, norma, dan peraturan; kedua, wujud kebudayaan sebagai suatu kompleks aktivitas tindakan berpola oleh manusia dalam masyarakat; dan ketiga, wujud kebudayaan sebagai benda hasil karya manusia. 
Ketiga wujud gejala kebudayaan itu saling terkait satu dengan lain. Wujud kebudayaan sebagai kompleks ide, gagasan, nilai, serta norma sifatnya mengatur dan memberi arah kepada aktivitas tindakan dan karya manusia. Pikiran, ide-ide, maupun tindakan karya manusia, dapat menghasilkan beberapa benda kebudayaan fisiknya. Dan sebaliknya, kebudayaan fisik dapat mempengaruhi pula pola-pola perbuatan, serta pikiran. Dari pandangan antropologi, biasanya melihat kebudayaan sebagai unsur yang terintegrasi. Keseluruhan unsur-unsur disebut unsur-unsur kebudayan yang bersifat universal atau cultural universal, bermacam-macam unsur itu dapat dipilahpilahkan menjadi tujuh unsur yaitu: bahasa, sistem pengetahuan, organisasi sosial, sistem peralatan dan teknologi, sistem pencaharian, sistem religi/kepercayaan, dan kesenian ( Koentjaraningrat, 1990:217-219).

Dari unsur sistem religi/kepercayaan di daerah Simalungun, dalam kehidupan masyarakat Simalungun masih menganut sistem kepercayaan animisme yang mempercayai roh-roh yang telah meninggal dunia, setiap masyarakat Simalungun yang beragama kristen melakukan puji-pujian dan doa-doa terhadap tuhannya menggunakan tari-tarian, nyanyinyanyian dan melalui benda-benda yang mereka anggap menjadi perantara untuk penyampaian doa-doa mereka.

Pada upacara adat sayurmatua, kehadiran tortor toping huda-huda mengandung makna-makna tertentu berdasarkan kepercayaan masyarakat pendukungnya. Para ahli menyatakan bahwa, makna adalah bagian yang tidak terpisahkan dari semantik dan selalu melekat dari apa saja yang dituturkan termasuk dalam gerakan. Hal ini sesuai pula dengan menurut Ferdinand De Saussure (dalam Abdul Chaer, 1994:286) yang mengungkapkan bahwa pengertian makna adalah sebagai suatukonsep yang dimiliki atau terdapat pada suatu tanda linguistic. Dalam proses untuk mengetahui makna, yang perlu dipahami adalah pola pikir harus sesuai dengan penerapan yang berstruktur baik dalam bentuk lisan maupun tulisan. Istilah makna dapat diartikan sebagai ungkapan yang menjelaskan suatu persepsi atau perilaku manusia atau kelompok manusia, yang menjelaskan berbagai dalam kehidupan bermasyarakat. Dalam menetapkan sebuah makna, perlu adanya sistem tanda-tanda yang disebut dengan simbol. Pengertian simbol menurut pandangan semiotik yaitu Saussure, diartikan sebagai hubungan antara bentuk dan makna tidak bersifat pribadi, tetapi sosial yakni didasari oleh kesepakatan (konvensi) sosial. Tanda sebagai pertemuan antara bentuk dan
Gorga Jurnal Seni Rupa

Volume 08 Nomor 01 Januari-Juni 2019

p-ISSN: 2301-5942 | e-ISSN: 2580-2380

makna, yang menggunakan istilah signifer (penanda) dan signified (petanda). Melihat tanda sebagai sesuatu yang menstruktur (proses pemaknaan berupa kaitan antara penanda dan petanda) dan struktur (hasil proses tersebut) di dalam kognisi manusia (Sausuure dalam Hoed, 2008:3-4).

Berdasarkan teori di atas, upacara adat sayurmatua sebagai unsur kebudayaan yang dilihat sebagai sistem simbol, yang menghubungkan manusia dengan manusia, dan manusia dengan tuhan. Dimana tortor toping huda-huda merupakan petanda bahwa ada orang tua yang sudah lanjut usia meninggal dunia, dan tortor toping huda-huda hanya hadir di upacara adat sayurmatua.

Dalam tarian tortor toping huda-huda terdapat gerak yang mengandung simbol dan makna untuk penyembahan kepada roh-roh yang telah meninggal dunia, dan penghormatan kepada tondong (pihak orang tua dari ibu atau saudara kandung), boru (saudara perempuan dari yang meninggal) dan para pelayat. Mereka mempercayai dengan properti yang digunakan penari huda-huda yaitu burung enggang akan membawa roh-roh yang meninggal dunia menghadap tuhan sang pencipta. Setiap gerakan tortor yang dilakukan penari, mengandung persembahan dan meminta ampun kepada tuhan.

Tari menurut agama Kristen sangatlah penting didalam kehidupan mereka, mereka menyembah, berdoa dan memuja tuhannya dengan menari dan bernyanyi, bahkan didalam alkitab mencatat bahwa tari-tarian sudah diciptakan Allah sebelum dunia dijadikan. Sebagaimana di dalam alkitabnya yang berbunyi sebagai berikut: "Bagaimana bangsa Israel menyembah patung anak lembu emas dalam taritarian ketika mereka sudah tidak sabar menantikan Musa membawa hukum Allah kepada mereka”. keluaran 32: 19. "Dimana para nabi baal menggunakan tari-tarian sebagai salah satu ritual untuk memanggil hujan pada peristiwa di gunung karmel”. I Raja-raja 18:26. "Tari-tarian, yang seharusnya menjadi bagian dari penyembahan kepada Allah, digunakan sebagai sarana untuk membunuh Yohanes Pembaptis". Injil Matius 14:6-8

Alasan mengapa mereka yang beragama kristen menari karena menurut didalam Alkitab mereka Allah adalah pribadi yang berekspresi, sebagaimana disebutkan didalam Alkitab tersebut yaitu:

"Tuhan Allahmu ada di antaramu sebagai pahlawan yang memberi kemenangan, ia membaharui engkau dalam kasih-Nya, ia 


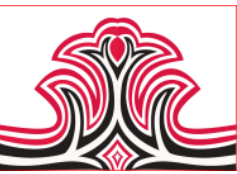

bersorak-sorak karena engkau dengan soraksorai, seperti pada hari pertemuan raya”.

Zefanya 1:17-18a

Sebagai satu-satunya makhluk yang diciptakan segambar dengan rupa Allah, manusia sewajarnya menyembah Allah dengan sepenuh hati dan dalam sepenuh ekspresi, termasuk ekspresi yang dilakukan melalui tari-tarian.

\section{KESIMPULA DAN SARAN \\ 1.Kesimpulan}

Berdasarkan penelitian yang dilakukan, sistem kepercayaan yang dilakukan dalam kehidupan masyarakat Simalungun Sumatera Utara masih mempercayai sistem animisme yang mempercayai roh-oh yang telah meninggal dunia, dari nilai-nilai religi yang dimiliki masyarakat Simalungun yang beragama Kristen di aplikasikan ke dalam sebuah seni yang di dalamnya terdapat tari-tarian dan musik atau nyanyi-nyanyian. Bisa dilihat pada tari toping hudahuda pada upacara kematian sayurmatua di Simalungun Sumatera Utara.

Tortor toping huda-huda adalah nalar atau proses berfikir orang Simalungun guna memahami kematian yang secara fungsional berupaya untuk memberikan gambaran terhadap kematian. Karena fungsi tarian ini adalah sebagai media simbolik memaknai kematian yang dilakonkan melalui gerak ritmis sebagai ekspresi jiwa atau rasa dalam memaknai kematian itu sendiri. Tarian ini juga sebagai hiburan pada saat kematian, sehingga yang ditinggal tidak larut dalam kesedihan, luka, lara dan derita. Gerak tor-tor pada tari ini merupakan bentuk komunikasi masyarakat Simalungun kepada tuhannya dan roh-roh yang telah meninggal dunia. Kemudian dapat dilihat pada musik toping huda-huda ini, iringan musik mengandung makna dan berisi nyanyian-nyanyian, puji-pujian yang mengandung kesedihan pada saat upacara kematian, masyarakat yang mendengarkan musik dan nyanyiannya akan merasa terharu dan menangis ketika mendengarkannya.

\section{Saran}

Berkaitan dengan penelitian mengenai tradisi dan kesenian dalam upacara sayurmatua yang terdapat dalam kebudayaan masyarakat khususnya bagi masyarakat Simalungun, harus menjaga dan melestarikan kebudayaan dan kesenian yang sudah menjadi tradisi turun temurun dalam suatu masyarakat. Begitu juga dengan tortor toping hudahuda yang sudah menjadi kesenian tradisi turun temurun yang hadir dalam suatu ritual upacara yang
Gorga Jurnal Seni Rupa

Volume 08 Nomor 01 Januari-Juni 2019

p-ISSN: 2301-5942 | e-ISSN: 2580-2380

sakral dan memiliki banyak makna yang tersirat di dalamnya. Sangatlah penting untuk melestarikan dan menjaga tradisi kebudayaan yang dimiliki agar tidak punah begitu saja.

\section{DAFTAR RUJUKAN}

Chaer, Abdul. (1994). Linguistik Umum. Jakarta: Rineka Cipta.

Cassier, Ernst. (1987). Manusia dan Kebudayaan: Sebuah Esei Tentang Manusia, Terj. Alois A. Nugroho. Jakarta: PT.Gramedia.

Endraswara, Suwardi. (2006). Mistik Kejawen (Sinkretisme, Simbolisme, dan Sufismedalam Budaya Spiritual Jawa). Yogyakarta: NARASI.

Hoed, Benny H. (2008). Mendekontruksi Mitos-mitos Masa Kini Semiotik dan Dinamika Sosial Budaya. Jakarta: Daras Books.

Koentjaraningrat. (1990). Pengantar Ilmu Antropologi. Jakarta: Rineka Cipta.

Koyama, M., Y. Hayakawa. (1949). Sunspot observations. In Japanese:

Sugono, D. (2008). Kamus Besar Bahasa Indonesia. Jakarta: Pusat Bahasa Departemen Pendidikan Nasional.

Turner, Victor. (2008). Liminality and Communitas, in The Ritual Process: Structure and AntiStructure, New Brunswick: Aldine Transaction Press. 